\title{
Plant growth promoting rhizobacteria with ACC deaminase activity isolated from Mediterranean dryland areas in Chile: Effects on early nodulation in alfalfa
}

\author{
George A. Cedeño-García1, ${ }^{1}$, Macarena Gerding²*, Gary Moraga², Luis Inostroza ${ }^{3}$, Susana Fischer², \\ Maurine Sepúlveda-Caamaño², and Pía Oyarzúa² \\ ${ }^{1}$ Universidad Técnica de Manabí, Facultad de Ingeniería Agronómica, km 13.5 vía Portoviejo-Santa Ana, Ecuador. \\ ${ }^{2}$ Universidad de Concepción, Facultad de Agronomía, Av. Vicente Méndez 595, Chillán, Chile. \\ *Corresponding author (mgerding@udec.cl). \\ ${ }^{3}$ Instituto de Investigaciones Agropecuarias, INIA Quilamapu, Av. Vicente Méndez 515, Chillán, Chile. \\ ${ }^{4}$ Universidad de Concepción, Programa de Doctorado en Ciencias de la Agronomía, Av. Vicente Méndez 595, Chillán, Chile.
}

Received: 7 May 2018; Accepted: 11 June 2018; doi:10.4067/S0718-58392018000300360

\begin{abstract}
Alfalfa (Medicago sativa L. subsp. sativa) has emerged as an alternative crop for Mediterranean dryland areas in Chile. These soils show deficient nutritional levels affecting legume nodulation and $\mathrm{N}$ fixation through symbiosis with Ensifer meliloti. The objective of this work was to select plant growth promoting rhizobacteria (PGPR) associated with alfalfa and to evaluate their effects in plant growth and nodulation. Bacterial strains were isolated from the rhizosphere of alfalfa cultivated in dryland soil in Mediterranean areas of Chile. The 1-aminocyclopropane-1-carboxylic acid (ACC) deaminase activity, production of indole acetic acid (IAA), phosphate solubilization and the compatibility with E. meliloti was assessed for each strain. The selected bacterial strains were identified by the amplification of the 16S rRNA gene. Twelve of the 32 isolated strains were compatible with E. meliloti as they did not show signs of antagonism. Eight strains solubilized phosphate, 12 produced IAA ranging from 13.71 to $26.22 \mathrm{mg} \mathrm{L}^{-1}$ and only the GN-8 isolate reported ACC deaminase activity. In the plants, the nodulation was greater when the strain with ACC deaminase and E. meliloti were co-inoculated both in laboratory and greenhouse conditions $(\mathrm{P}<0.05)$. The selected bacteria GN-2 and GN-8 belonged to the genus Bacillus, while GN-4 to Pseudomonas. In conclusion, PGPR collected in marginal soils of Mediterranean areas of Chile showed ACC deaminase activity, IAA production and phosphate solubilization. The co-inoculation with $E$. meliloti and Bacillus sp. GN-8 allowed earlier nodulation in alfalfa.
\end{abstract}

Key words: ACC deaminase, alfalfa, Medicago sativa, nodulation, PGPR, phosphate solubilization, indole acetic acid.

\section{INTRODUCTION}

Alfalfa (Medicago sativa L. subsp. sativa) is the most important and widely grown forage legume in the world (Bouton, 2012). Alfalfa establishes a symbiotic mutualistic relationship with the bacteria Ensifer (Sinorhizobium) meliloti, through the formation of a root structure called nodule where $\mathrm{N}$ fixation occurs (Pini et al., 2012). Nodulation in legumes is a process regulated by biochemical signals between plant and bacteria through flavonoid aromatic compounds secreted by the plant, and bacterial compounds known as Nod Factors (Ji et al., 2017). Early nodulation is the key for a better 
establishment of this symbiotic relationship to ensure increased $\mathrm{N}$ fixation and plant biomass production (Pini et al., 2012). Alfalfa can achieve fixation levels of $120-800 \mathrm{~kg} \mathrm{~N} \mathrm{ha}^{-1}$. However, in environments with adverse conditions for the rhizobia such as the Mediterranean dryland area of Chile, nodulation and symbiotic effectiveness in alfalfa may be drastically reduced (del Pozo et al., 2017). Nodulation is inhibited by the increase of ethylene in response to defense signals from interactions of plants with other microorganisms and very often by periods of droughts and soil salinity (Shahzad et al., 2010; Barnawal et al., 2014).

Significant improvements in nodulation have been reported through inoculation with plant growth promoting rhizobacteria (PGPR) able to produce indole acetic acid (IAA) and with 1-aminocyclopropane-1-carboxylic acid (ACC) deaminase activity (Rashid et al., 2012; Sepúlveda-Caamaño et al., 2018). The presence of ACC deaminase-producing bacteria in the root system reduces ethylene biosynthesis and increases the number of nodules, and produces changes in root architecture by promoting the development of lateral roots (Shahzad et al., 2010). This is because 1-aminocyclopropane1-carboxylic acid (ACC) deaminase enzyme degrades and consumes the ethylene precursor ACC or inhibits the enzyme ACC synthase (Hardoim et al., 2008). When the ethylene precursor ACC is broken by the enzyme ACC deaminase, it is converted to alpha-ketobutyrate and ammonium, providing the bacteria with a source of N (Penrose and Glick, 2003). Co-inoculating legumes with bacteria with ACC deaminase activity and rhizobia, can improve nodulation by up to $40 \%$, therefore enhancing N fixation (Ma et al., 2004; Shahzad et al., 2010; Glick, 2014).

The objectives of this research were to select PGPR from alfalfa rhizosphere with ACC deaminase activity, capable of producing IAA and solubilizing phosphate and to evaluate the effect of the co-inoculation Ensifer meliloti-PGPR on early nodulation in alfalfa plants.

\section{MATERIALS AND METHODS}

\section{Collection and isolation of bacteria}

Soil and alfalfa plants (10 samples) were collected from a rainfed area in Mediterranean central Chile, Cauquenes (35 $\left.57^{\prime} 20.63^{\prime \prime} \mathrm{S}, 72^{\circ} 17^{\prime} 9.14^{\prime \prime} \mathrm{W}\right)$, an area characterized by granitic soils (Ultic Palexeralf), a soil $\mathrm{pH}$ of $7.0,1.6 \%$ organic matter content, $2.3 \mathrm{mg} \mathrm{kg}^{-1}$ available mineral N, $12 \mathrm{mg} \mathrm{P} \mathrm{kg}^{-1}$ and $185 \mathrm{mg} \mathrm{K} \mathrm{kg}^{-1}$ in the top $20 \mathrm{~cm}$. To isolate bacteria from the endorhizosphere, the protocol described by Sepúlveda-Caamaño et al. (2018) was used, where $1 \mathrm{~g}$ root was disinfected by immersion in $70 \%(\mathrm{v} / \mathrm{v})$ ethanol for $30 \mathrm{~s}$ and rinsed in sterile distilled water for $1 \mathrm{~min}$. To isolate bacteria from the exorhizosphere, $1 \mathrm{~g}$ soil firmly attached to the root was used. Samples of disinfected roots and soil were separately macerated in sterile mortars in $100 \mathrm{~mL}$ phosphate-buffered saline (PBS) solution $\left(0.9 \% \mathrm{NaCl}(\mathrm{v} / \mathrm{v}), 2.9 \mathrm{mM} \mathrm{KH} \mathrm{KO}_{4}, 7.1\right.$ $\left.\mathrm{mM} \mathrm{K}_{2} \mathrm{HPO}_{4}, \mathrm{pH} 7.2\right)$ and stirred for $2 \mathrm{~h}$ at $150 \mathrm{rpm}$. The suspensions were diluted to concentrations of $10^{-3}$; from each dilution, $0.1 \mathrm{~mL}$ was inoculated in Petri dishes with standard nutrient agar medium (Merck, Kenilworth, New Jersey, USA) and incubated at $25^{\circ} \mathrm{C}$ for $48 \mathrm{~h}$. Isolated colonies with distinctive morphological characteristics were selected and re-isolated on standard nutrient agar to obtain pure cultures. The isolates were cryopreserved at $-80{ }^{\circ} \mathrm{C}$ in $20 \%$ glycerol (Oskouei et al., 2010).

\section{PGPR compatibility with Ensifer meliloti}

The capacity of the plant growth promoting rhizobacteria (PGPR) isolates to grow together with the alfalfa specific inoculant E. meliloti strain AG-06 was tested. For this purpose, the rhizobacterial strains, in addition to AG-06 were placed in $5 \mathrm{~mL}$ of sterile saline solution $(0.98 \% \mathrm{w} / \mathrm{v})$ and the optical density was adjusted to $600 \mathrm{~nm}$ wavelength $\left(\mathrm{OD}_{600}\right)$ at 0.1 . The suspensions were inoculated into nutrient agar plates and superficially distributed with a glass rod and were incubated at $25^{\circ} \mathrm{C}$. An agar disc showing bacterial growth was placed on the plates inoculated with E. meliloti, kept in incubation at $25^{\circ} \mathrm{C}$ for $24 \mathrm{~h}$ prior to evaluation. When E. meliloti was not able to grow around the bacterial disc, the strain was discarded from future experiments. Only the isolates that were compatible with E. meliloti strain AG-06 were selected for the following experiments.

\section{ACC deaminase activity of PGPR selected}

An aliquot of $100 \mu \mathrm{L}$ of suspended cells $\left(10^{7} \mathrm{CFU} \mathrm{mL}^{-1}\right)$ of the selected strains, were inoculated onto $3 \mathrm{~mL}$ nutrient broth and incubated for $24 \mathrm{~h}$ at $200 \mathrm{rpm}$ at a constant temperature of $25^{\circ} \mathrm{C}$. Then $1 \mathrm{~mL}$ of cell suspension was transferred to 
microtubes and centrifuged at $8000 \mathrm{rpm}$ for $10 \mathrm{~min}$ at $4{ }^{\circ} \mathrm{C}$. The supernatant was extracted and washed twice in DworkinFoster (DF) minimal salts medium (Dworkin and Foster, 1958) and centrifuged at $8000 \mathrm{rpm}$ for $10 \mathrm{~min}$ at $4{ }^{\circ} \mathrm{C}$. The cell pellet was then suspended in $500 \mu \mathrm{L}$ DF minimal media and incubated in a rotary shaker at $200 \mathrm{rpm}$ and $25{ }^{\circ} \mathrm{C}$ for $24 \mathrm{~h}$. Bacterial strains were inoculated onto three different media: Plates with $30 \mathrm{~mL}$ DF agar; DF agar with $1.5 \%$ 1-aminocyclopropane-1-carboxylic acid (ACC), and DF agar with $\left(\mathrm{NH}_{4}\right)_{2} \mathrm{SO}_{4}$ as $\mathrm{N}$ source (Penrose and Glick, 2003). A droplet of $5 \mu \mathrm{L}$ of each strain was placed on each media. Strains with ACC deaminase activity: Pseudomonas sp. 8R6 wild type (WT) and Pseudomonas fluorescens YsS6 WT were included as positive controls; and two ACC deaminase mutant (acds) mutant strains, 8R6 acds and YsS6 acds, were included as negative controls (Rashid et al., 2012). Colony growth was observed daily for $5 \mathrm{~d}$.

\section{Phosphate solubilization of PGPR selected}

Phosphate solubilization was evaluated according to Chaiharn and Lumyong (2011). The isolates were grown in standard nutrient broth (Merck), shaken for $48 \mathrm{~h}$ at $150 \mathrm{rpm}$ at $25^{\circ} \mathrm{C}$. Plates with Pikovskaya agar (glucose $10 \mathrm{~g}, \mathrm{Ca}_{3}\left(\mathrm{PO}_{4}\right) 25 \mathrm{~g}$, $\mathrm{KCl} 0.2 \mathrm{~g},\left(\mathrm{NH}_{4}\right)_{2} \mathrm{SO}_{4} 0.5 \mathrm{~g}, \mathrm{MgSO}_{4} \cdot 7 \mathrm{H}_{2} \mathrm{O} 0.1 \mathrm{~g}$, yeast extract $0.5 \mathrm{~g}, \mathrm{MnSO}_{4}$ traces, $\mathrm{FeSO}_{4}$ traces, $15 \mathrm{~g}$ agar, $1000 \mathrm{~mL}$ distilled water, $\mathrm{pH}$ 7-7.5) were inoculated with $4 \mu \mathrm{L}$ pure bacterial culture. They were incubated at $25^{\circ} \mathrm{C}$ for $48 \mathrm{~h}$ and the formation of the transparent halo was observed in each colony.

To quantify the solubilized phosphate, bacterial isolates capable of solubilizing phosphate were inoculated in sterile Falcon tubes with $10 \mathrm{~mL}$ Pikovskaya liquid medium (glucose $10 \mathrm{~g}, \mathrm{Ca}_{3}\left(\mathrm{PO}_{4}\right) 25 \mathrm{~g}, \mathrm{KCl} 0.2 \mathrm{~g},\left(\mathrm{NH}_{4}\right)_{2} \mathrm{SO}_{4} 0.5$ $\mathrm{g}, \mathrm{MgSO}_{4} \cdot 7 \mathrm{H}_{2} \mathrm{O} 0.1 \mathrm{~g}$, yeast extract $0.5 \mathrm{~g}, \mathrm{MnSO}_{4}$ traces, $\mathrm{FeSO}_{4}$ traces, distilled water $\left.1000 \mathrm{~mL}, \mathrm{pH} 7.3\right)$. In addition, a sample of Pikovskaya liquid medium without inoculation was used as control. Samples were incubated for $3 \mathrm{~d}$ in an orbital shaker at $150 \mathrm{rpm}$ and $25^{\circ} \mathrm{C}$. Samples were then centrifuged $(5804 \mathrm{R}$ centrifuge, Eppendorf International, Hamburg, Germany) at $11000 \mathrm{rpm}$ for $2 \mathrm{~min}$ at $26^{\circ} \mathrm{C}$, and $4 \mathrm{~mL}$ supernatant was removed and transferred to new tubes. To quantify the solubilized P-PO ${ }_{4}$, for method of Sadzawka et al. (2004), and Undurraga et al. (2017) was applied with modifications. On $0.5 \mathrm{~mL}$ of supernatant, $1.5 \mathrm{~mL}$ distilled water were added plus $8 \mathrm{~mL}$ of the color development reagent.

\section{IAA production of PGPR selected}

Production of indole acetic acid (IAA) was evaluated for the 12 selected bacterial strains. A $100 \mu \mathrm{L}$ cell suspension was inoculated into $30 \mathrm{~mL}$ capacity glass test tubes with $5 \mathrm{~mL}$ nutrient broth (Merck), which were shaken for $24 \mathrm{~h}$ at 150 $\mathrm{rpm}$ at $25^{\circ} \mathrm{C}$. From the bacterial suspension, $1 \mathrm{~mL}$ was transferred into $2 \mathrm{~mL}$ eppendorf tubes, which were centrifuged at $10000 \mathrm{rpm}$ for $10 \mathrm{~min}$, then $600 \mu \mathrm{L}$ supernatant were transferred to an eppendorf tube and $400 \mu \mathrm{L}$ modified Salkowski reagent $\left(0.5 \mathrm{M} \mathrm{FeCl}_{3}\right.$ and $35 \%$ perchloric acid) were added. After $30 \mathrm{~min}$ of standing at room temperature, absorbance was measured in a spectrophotometer (MRC, POP OPTIZEN BIO, Korea) at a wavelength of $535 \mathrm{~nm}$. The calibration curve was determined using IAA at concentrations from 0 to $50 \mathrm{mg} \mathrm{L}^{-1}$. The absorbance data and IAA concentrations were adjusted to a linear regression $(\mathrm{R}=0.999 ; \mathrm{P}=<0.001)$.

\section{Evaluation of nodulation rate in alfalfa plants}

The strains GN-2, selected for higher IAA production and phosphate solubilization, GN-4 selected for phosphate solubilization, and GN-8 for ACC deaminase activity, were co-inoculated with E. meliloti (AG-06) on alfalfa seedlings. Incu tissue vials $500 \mathrm{~cm}^{3}$, were filled to half volume with a sterilized substrate consisting of rock mineral wool and vermiculite 1:1 (v/v). Alfalfa seeds 'Alta Sierra Illapata' were disinfected by immersion in separate solutions of 70\% (v/v) ethanol for $1 \mathrm{~min}, 3 \%(\mathrm{v} / \mathrm{v})$ sodium hypochlorite $3 \mathrm{~min}$, and then washed six times in sterile distilled water. Six seeds were sown per vial, and after emergence they were thinned to three. Once emerged, seedlings were inoculated with $1 \mathrm{~mL}$ bacterial suspension in $1 \%(\mathrm{w} / \mathrm{v})$ sucrose at a $\mathrm{DO}_{600} \mathrm{~nm}$ of 0.1 , additionally $20 \mathrm{~mL} \mathrm{~N}$-free nutrient solution was added (0.31 g L-1 $\mathrm{MgSO}_{4} \cdot 7 \mathrm{H}_{2} \mathrm{O} ; 0.21 \mathrm{~g} \mathrm{~L}^{-1} \mathrm{KH}_{2} \mathrm{PO}_{4} ; 0.44 \mathrm{~g} \mathrm{~L}^{-1} \mathrm{~K}_{2} \mathrm{SO}_{4} ; 0.06 \mathrm{~g} \mathrm{~L}^{-1}$ FeEDTA; $0.05 \mathrm{~g} \mathrm{~L}^{-1} \mathrm{CaSO}_{4} ; 0.116 \mathrm{mg} \mathrm{L}^{-1}$ $\mathrm{H}_{3} \mathrm{BO}_{3} 0.116 ; 0.0045 \mathrm{mg} \mathrm{L}^{-1} \mathrm{Na}_{2} \mathrm{MoO}_{4} \cdot 2 \mathrm{H}_{2} \mathrm{O} ; 0.134 \mathrm{mg} \mathrm{L}^{-1} \mathrm{ZnSO}_{4} \cdot 7 \mathrm{H}_{2} \mathrm{O} ; 0.01 \mathrm{mg} \mathrm{L}^{-1} \mathrm{MnSO}_{4}, 4 \mathrm{H}_{2} \mathrm{O}$ and $0.06 \mathrm{mg} \mathrm{L}^{-1}$ $\mathrm{CoSO}_{4} \cdot 7 \mathrm{H}_{2} \mathrm{O}$ ). An uninoculated control was also included. The pots were kept in a phytotron with high pressure sodium lamps (400 W Gro-lux, Osram Sylvania Ltd., Danvers, Massachusetts, USA) with a minimum photosynthetic photon flux density (PPFD) of 400-500 mol m-2 $\mathrm{s}^{-1}$. Nodulation was assessed at 15, 25, and $35 \mathrm{~d}$ after inoculation. Four replicates were used per treatment applied. 


\section{Endophytic capacity of bacterial strains}

Using the plants from the previous assay the endophytic capacity of the bacterial strains was determined according to the protocol by Parsa et al. (2013). Root and shoot fragments $3 \mathrm{~cm}$ long were washed in distilled water and disinfected superficially in $70 \%$ ethanol for $2 \mathrm{~min}$, followed by immersion in $1 \%$ hypochlorite for $30 \mathrm{~s}$, and finally four washes in sterile distilled water. The fragments were cut into $1 \mathrm{~cm}$ segments and sowed in standard nutrient agar plates, incubated for $48 \mathrm{~h}$ at $25{ }^{\circ} \mathrm{C}$. The bacterial colonies developed from the ends of the cuts were re-isolated on standard nutrient agar and subject to the same growth conditions mentioned above. The same procedure was also performed with the nodules.

The obtained isolates were characterized by BOX-PCR genomic fingerprint using the primer BOXA1R (5'-CTA CGG CAA GGC GAC GCT GAC G-3') (Guiñazú et al., 2013) in order to verify if they corresponded to the same strain applied in the inoculation treatments. The cell template was prepared by suspending three loops full of bacterial cells in sterile saline solution, which were washed 3 times via centrifugation at $5000 \mathrm{~g}$ for $5 \mathrm{~min}$, and suspension in nuclease-free water, adjusted to $\mathrm{OD}_{600}=1.5$. The sample was then subjected to a heat shock of $65{ }^{\circ} \mathrm{C}$ for $5 \mathrm{~min}$ and $-20{ }^{\circ} \mathrm{C}$ for $5 \mathrm{~min}$. The BOX-PCR reaction mixture consisted of $5.0 \mu \mathrm{L}$ cell suspension, $0.3 \mu \mathrm{L}$ GoTaq DNA polymerase (Promega, Madison, Wisconsin, USA), $5.0 \mu \mathrm{L}$ primer BOXA1R $(10 \mu \mathrm{M}), 1.5 \mu \mathrm{L} \mathrm{MgCl}_{2}(25 \mathrm{mM}), 5.0 \mu \mathrm{L} 5 \mathrm{x}$ GoTaq Buffer (Promega), 0.5 $\mu \mathrm{L}$ dNTPs $(10 \mathrm{mM}$ ) and $7.7 \mu \mathrm{L}$ ultra pure water (Fisher Biotech, Wembley, Western Australia, Australia) to complete 25 $\mu \mathrm{L}$ (Marques et al., 2008). The PCR conditions were $95^{\circ} \mathrm{C}$ for $7 \mathrm{~min}, 35$ cycles at $94{ }^{\circ} \mathrm{C}$ for $1 \mathrm{~min}, 52{ }^{\circ} \mathrm{C}$ for $1 \mathrm{~min}$ and $72{ }^{\circ} \mathrm{C}$ for $8 \mathrm{~min}$, with a final extension at $72{ }^{\circ} \mathrm{C}$ for $16 \mathrm{~min}$ (Guiñazú et al., 2013). PCR products were analyzed by prestained 2\% (w/v) agarose gel electrophoresis with 1:10 000 GelRed DNA gel stain (Biotium, Fremont, California, USA). Electrophoresis was carried out in the $1 \times$ TAE buffered electrophoresis chamber $(40 \mathrm{mM}$ Tris-acetate, $1 \mathrm{mM}$ EDTA, pH 8.0) at $100 \mathrm{~V}$ for $3 \mathrm{~h}$, then the bands were visualized in a UV transilluminator.

\section{Identification of bacterial isolates}

To identify the bacterial strains selected for the plant assay, partial amplification and sequencing of 16S ribosomal DNAgene was performed, using the primers $8 \mathrm{~F}$ (AGAGTTTGATCCTGGCTCAG) and 1492R (GGCTACCTTGTTACGACTT) (Sepúlveda-Caamaño et al., 2018). A reaction mixture was prepared with $2 \mu \mathrm{L}$ cell preparation, $0.5 \mu \mathrm{L}$ Taq polymerase (Invitrogen Life Technologies, Carlsbad, California, USA), $1 \mu \mathrm{L}$ primers $8 \mathrm{~F}$ and $1492 \mathrm{R}, 6.0 \mu \mathrm{L} 25 \mathrm{mM} \mathrm{MgCl} 2,20.0 \mu \mathrm{L}$ 5x Fisher-Biotech polymerization Buffer and $69.5 \mu \mathrm{L}$ ultra pure water to complete $100 \mu \mathrm{L}$ per reaction. The PCR cycles were: $7 \mathrm{~min}$ at $95{ }^{\circ} \mathrm{C}$ followed by 35 cycles of $94^{\circ} \mathrm{C}$ for $30 \mathrm{~s}, 62^{\circ} \mathrm{C}$ for $30 \mathrm{~s}$ and $72{ }^{\circ} \mathrm{C}$ for $45 \mathrm{~s}$, finally $72{ }^{\circ} \mathrm{C}$ for $5 \mathrm{~min}$. Amplification of the genes was verified by electrophoresis. The PCR products were purified and sequenced at Macrogen Inc. (Seoul, Korea). Partial sequences of the 16S rRNA genes were analyzed with GeneTool Lite 1.0 software (2000, Doubletwist, Inc., Oakland, California, USA). Sequence alignment and phylogenetic analyzes were carried out in MEGA 5.2 (Tamura et al., 2011). The phylogenetic tree was constructed using the Neighbor-joining test with 1000 replicates. Type strains included in the phylogenetic tree were obtained from GenBank of the National Center for Biotechnology Information (NCBI, Bethesda, Maryland, USA).

\section{Greenhouse experiment}

The experiment was carried out in a polycarbonate greenhouse at the Instituto de Investigaciones Agropecuarias (INIA), Quilamapu facilities, Chillán, Chile. Pots consisted in PVC plastic tubes of $11 \mathrm{~cm}$ in diameter $\times 100 \mathrm{~cm}$ high $(11 \mathrm{~L}$ volume). The substrate was a mixture of perlite and vermiculite $1: 1(\mathrm{v} / \mathrm{v})$, with a water retention capacity on a dry weight basis of $172 \%$. The substrate was autoclaved at $90{ }^{\circ} \mathrm{C}$ for $15 \mathrm{~min}$. Alfalfa seeds were disinfected as described before. Six seeds were sown in each pot, and $10 \mathrm{~d}$ after sowing were thinned to two. Plants were irrigated with $20 \mathrm{~mL}$ of the $\mathrm{N}$ free nutrient solution at a weekly basis.

The strains used in this trial were GN-8 isolated from alfalfa and AG-30 (YsS6 WT) as a positive control (Rashid et al., 2012), both with ACC deaminase activity, in co-inoculation with E. meliloti AG-06. The inoculation was carried out at plant emergence with $1 \mathrm{~mL}$ bacterial suspension at a $\mathrm{DO}_{600}$ of 0.06 . In addition, $1 \mathrm{~mL}$ E. meliloti AG-06 inoculum at $\mathrm{DO}_{600}$ of 0.1 was added. The inoculation was repeated after $8 \mathrm{~d}$. Nodulation, root development, and aerial dry weight evaluations were performed $60 \mathrm{~d}$ after sowing. The root was carefully harvested, cleaned and washed free of soil. The root length was measured and the number of nodules per plant was determined. The nodules were placed in Eppendorf tubes and dried for $48 \mathrm{~h}$ at $70{ }^{\circ} \mathrm{C}$, to determine their dry weight. Data were analyzed through an ANOVA and the comparison of means through the LSD test $(\mathrm{P} \leq 0.05)$. 


\section{RESULTS AND DISCUSSION}

\section{Characterization of bacterial strains}

A total of 32 bacterial strains were isolated from alfalfa rhizosphere from Cauquenes, a dryland area marked by water deficit (del Pozo et al., 2017). Among plant growth promoting bacteria, there are those that live in the exorhizosphere of plants and others that are found in the tissues of roots and stems (Nascimento et al., 2012), showing different specific functions that promote plant growth and development, especially in soils with limited nutritional levels or with adverse physical and chemical properties for plant growth and development (Egamberdiyeva, 2007). Since the rhizobacteria isolates were intended to be used as co-inoculants to improve the symbiotic performance of E. meliloti strain AG-06, 20 of the 32 isolates were discarded as they were incompatible with AG-06 showing antagonistic activity towards the rhizobial inoculant. Thus, the remaining 12 strains are shown in Table 1. The selection of PGPR strains compatible with the specific rhizobia has enabled successful inoculation and improvements in many aspects of growth in some legume crops such as soybeans, beans and chickpeas (Masciarelli et al., 2014), nodulation rates being the most favored in both, optimal growth conditions and under abiotic stress (Yadav and Prakash, 2014).

The 12 selected strains produced IAA at varying concentrations, ranging from 13.71 to $26.22 \mathrm{mg} \mathrm{IAA} \mathrm{L}^{-1}$ (Table 1). Among bacterial strains, GN-2, GN-7, GE-4 and GE-5 outstood for producing significantly higher amounts of IAA compared to other strains. IAA is a key regulator of plant growth, as it participates in metabolic processes such as elongation and cell division, apical dominance, tropism and vascular differentiation (Glick, 2014). The synthesis of bacterial IAA is generated from tryptophan as a direct precursor through three synthesis pathways (Duca et al., 2014), and its concentration is regulated by the ability of each bacterial strain and not by the concentration of tryptophan (Rashid et al., 2012). The effect of bacterial IAA production on plants has been widely reported in different crops (Ali et al., 2004), significantly improving physiological and agronomic parameters (Barrucha et al., 2013). IAA compounds play an important role in the formation of lateral and adventitious roots (Kisiel and Kepczynska, 2016), and in the proliferation of cortical cells at the time of nodulation and expression of ligated genes in early nodulation (Suzaki et al., 2013).

Of the 12 bacterial strains evaluated for phosphate solubilization, eight formed solubilization halos on Pikovskaya agar.

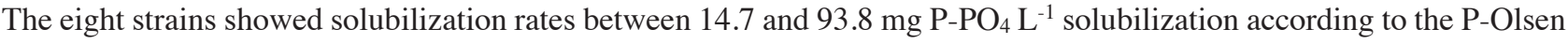
test, with GN-7 and GN-9 strains being superior, although statistically similar to GN-2 and GN-11 (Table 1). Phosphorus is the second most important nutrient for crops, but many soils worldwide are deficient in this mineral (Oufdou et al., 2016). The importance of phosphate-solubilizing bacteria in agriculture is well grounded as biofertilizers (Sharma et al., 2013; Oufdou et al., 2016), because of the ability of bacteria to solubilize the inorganic $\mathrm{P}$ of the soil through diverse processes into phosphate that is available to plants, increasing crop production (Chaiharn and Lumyong, 2011).

Table 1. Bacterial strains isolated from rhizosphere of alfalfa: compatibility with Ensifer meliloti, indol acetic acid (IAA) production, phosphate solubilization and 1-aminocyclopropane1-carboxylic acid (ACC) deaminase activity.

\begin{tabular}{llccc}
\hline Strain & \multicolumn{1}{c}{ Origin } & $\begin{array}{c}\text { Phosphate } \\
\text { solubilization } \mathrm{PO}_{2}\end{array}$ & IAA production & $\begin{array}{c}\text { ACC deaminase } \\
\text { activity }\end{array}$ \\
\cline { 3 - 4 } GN-1 & Endorhizosphere & $14.70 \mathrm{~d}$ & $18.14 \mathrm{bc}$ & - \\
GN-2 & Endorhizosphere & $90.73 \mathrm{ab}$ & $26.22 \mathrm{a}$ & - \\
GN-4 & Endorhizosphere & $15.13 \mathrm{c}$ & $15.13 \mathrm{c}$ & - \\
GN-7 & Endorhizosphere & $93.77 \mathrm{a}$ & $22.47 \mathrm{ab}$ & + \\
GN-8 & Endorhizosphere & - & $14.03 \mathrm{c}$ & - \\
GN-9 & Endorhizosphere & $93.37 \mathrm{a}$ & $19.07 \mathrm{bc}$ & - \\
GN-15 & Endorhizosphere & - & $15.70 \mathrm{bc}$ & - \\
GN-18 & Endorhizosphere & - & $13.71 \mathrm{c}$ & - \\
GE-4 & Exorhizosphere & $80.50 \mathrm{~b}$ & $19.70 \mathrm{abc}$ & - \\
GE-5 & Exorhizosphere & - & $20.13 \mathrm{abc}$ & - \\
GE-6 & Exorhizosphere & $88.40 \mathrm{ab}$ & $16.79 \mathrm{bc}$ & $17.18 \mathrm{bc}$ \\
GE-11 & Exorhizosphere & $87.05 \mathrm{ab}$ & & - \\
\hline
\end{tabular}

Different letters represent significant differences according to LSD test $(\mathrm{P}<0.05)$

GN: Isolated from the endorhizosphere; GE: isolated from the exorhizosphere. 
Of the evaluated strains only the bacterial strain GN-8 showed ACC deaminase activity (Table 1). The enzyme ACC deaminase degrades and consumes the precursor of ethylene 1-amino-cyclopropane carboxylic acid (ACC) (Glick, 2014), or inhibits the enzyme ACC synthase (Hardoim et al., 2008). Upon breaking the ethylene precursor ACC, it is converted to alpha-ketobutyrate and ammonium, providing the bacteria with a source of N (Penrose and Glick, 2003). The ACC deaminase activity has been reported to improve nodulation in legumes by counteracting inhibition in the elongation of infection threads and decreasing the senescence rate of nodules caused by ethylene (Hardoim et al., 2008; Zafar et al., 2012; Glick, 2014).

\section{Identification of PGPR strains}

Bacterial strains GN-2, GN-4, and GN-8 were identified at the species level by amplification and sequencing of the partial $16 \mathrm{~S}$ rRNA gene. The amplified fragment was $1200 \mathrm{bp}$. The phylogenetic tree of the 16S rRNA shows that the strain GN-4 is grouped in the Pseudomonas clade, with a sequence similarity of 99\% to Pseudomonas fluorescens (Figure 1). However, the GN-2 and GN-8 strains were grouped in the Bacillus clade, specifically GN-2 was close to Bacillus muralis with $99 \%$ sequence similarity and GN-8 to Bacillus niacini (Figure 1). Bacterial strains of the genus Pseudomonas and Bacillus have been reported as plant growth promoters in alfalfa (Guiñazú et al., 2013; Kisiel and Kepczynska, 2016), with ability to synthesize IAA, to solubilize P and showing ACC deaminase activity (Rashid et al., 2012; Kisiel and

Figure 1. Neighbor joining phylogenetic tree based on 16S rRNA sequencing of bacterial isolates GN-2, GN-4, and GN8. Bootstrap values are indicated on branches only when higher than 70. The type strains sequences in the phylogram were obtained from GenBank (accession number in parentheses).

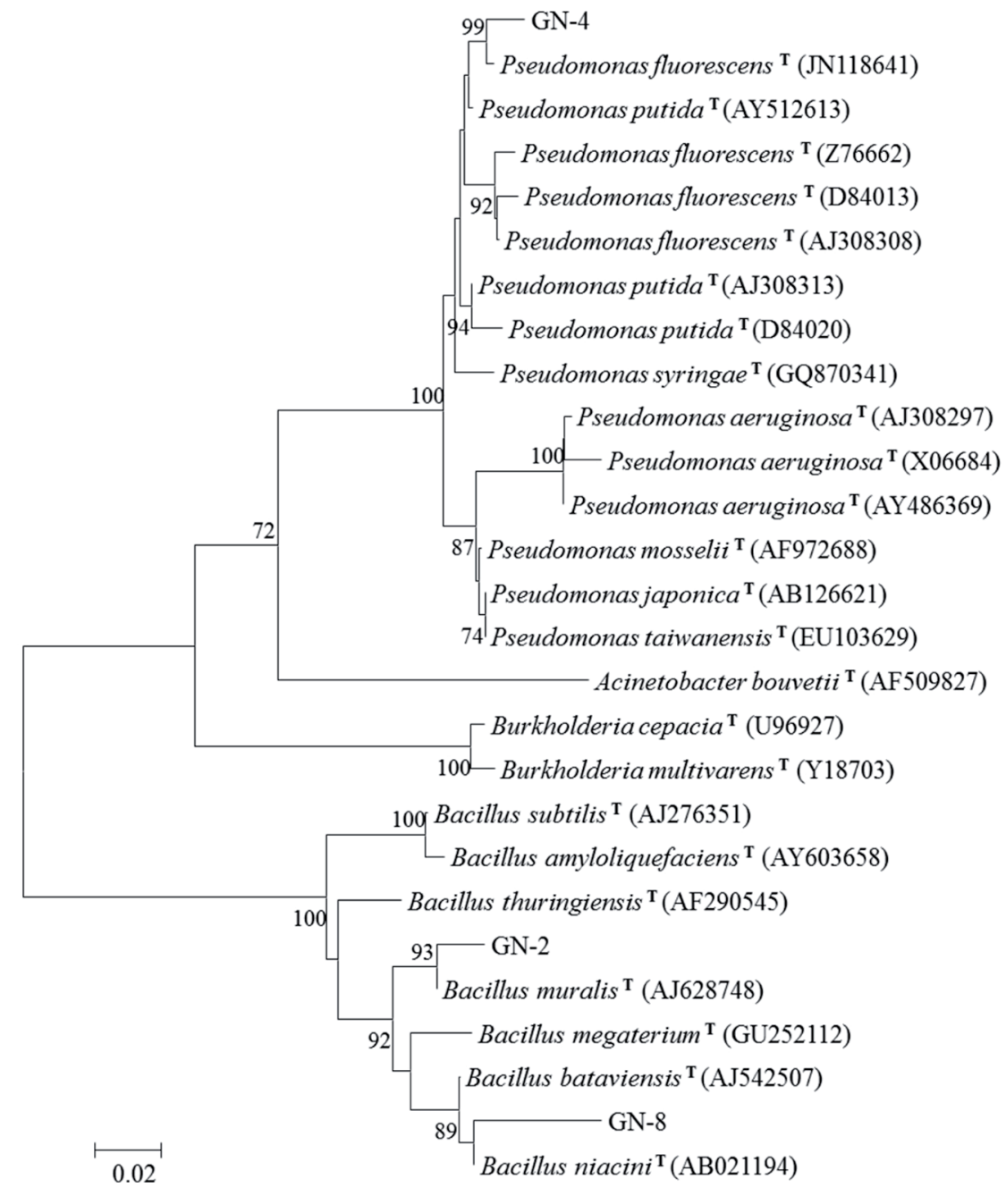


Kepczynska, 2016). Since the sequencing of the 16S rRNA gene is not always sufficient to determine a species, because it is a slowly evolving gene compared to other housekeeping genes (Sepúlveda-Caamaño et al., 2018), sequencing of other conserved genes will be necessary to obtain the definitive identification.

\section{Endophytic capacity}

From the plant tissue samples of alfalfa plants inoculated with PGPR under controlled conditions, 44 bacterial isolates were obtained. However, the BOX-PCR fingerprints showed that only the strain GN-4 could be recovered from plant tissues being able to colonize upper tissues such as stem. Bacterial endophytes can enter seeds through vascular connections, or directly through gametes colonizing the embryo (Truyens et al., 2015). All strains used for the plant trial were initially isolated from the alfalfa endorhizosphere. However, according to these results, the colonization of the endorhizosphere does not necessarily ensure its establishment as an endophyte in other tissues of the plant. The endophytic capacity of a bacterium is based on genomic differences in relation to soil rhizospheric bacteria (Ali et al., 2014), and also on the production of metabolic compounds necessary to overcome the microbiological competition in the rhizosphere, which endophytes need to colonize before invading plant tissue (Brader et al., 2014).

\section{Effect of co-inoculation $E$. meliloti + PGPR on early nodulation}

All the alfalfa plants were nodulated $15 \mathrm{~d}$ after inoculation, but plants inoculated with PGPR plus E. meliloti (AG-06) outstood in nodulation compared to treatment with only AG-06 although nonsignificant differences were found at this point (Table 2). Twenty-five days after inoculation the nodulation was significantly higher $(\mathrm{P}<0.05)$ when co-inoculated with GN-8 (ACC deaminase producer) compared to treatments co-inoculated with the other PGPR and to the control treatment inoculated only with E. meliloti (AG-06) (Table 2). After 35 d, nodulation was similar for all inoculation treatments (Table 2). In legumes, where $\mathrm{N}$ nutrition depends on the biological fixation of atmospheric $\mathrm{N}$, the number of nodules in the roots is indispensable for this process (Masciarelli et al., 2014). The strain GN-8 with ACC deaminase activity had a greater effect on nodulation compared to the IAA-producing strain GN-2 (Table 2). The presence of ACCdeaminase improves auxin response factor synthesis and reduces ethylene levels in the nodules (Ghosh et al., 2015). This allows the accumulation of IAA favoring the formation of nodules and other mechanisms of growth promotion (Ghosh et al., 2015). Also the reduction of ethylene levels by ACC-deaminase, promotes the elongation of infection thread in nodule formation and decreases the senescence rate of nodules (Glick, 2014). In this trial, Sinorhizobium-PGPR co-inoculation had no effect on root growth on alfalfa (Table 2).

\section{Greenhouse trial}

The effect of the bacterial strain with ACC deaminase activity GN-8 on nodulation on alfalfa was evaluated under greenhouse conditions and compared to the effect of AG-30 (YsS6 WT) (Rashid et al., 2012). The nodulation was higher in both inoculated treatments, resulting in an increase in the number of nodules of $18 \%$ with GN-8 and $118 \%$ with AG-30 in relation to the control inoculated with E. meliloti only. However, this improvement was significant only in the case of AG-30 ( $\mathrm{P}<0.05)$ (Table 3). Exogenous expression of an ACC deaminase gene in Mesorhizobium ciceri has increased nodulation in chickpea significantly up to $200 \%$ (Nascimento et al., 2012). A study by Guiñazú et al. (2013) shows similar results of the effect of bacterial strains of the genus Bacillus and Pseudomonas on nodulation in

Table 2. Effect of inoculation the Ensifer meliloti AG-06 and plant growth promoting rhizobacteria (PGPR) on nodule score and root length in alfalfa in phytotron chambers.

\begin{tabular}{llllll}
\hline & \multicolumn{2}{c}{ Root length } & & \multicolumn{2}{c}{ Nodule score } \\
\cline { 2 - 3 } \cline { 5 - 6 } Inoculants & $\mathrm{cm}$ & $15 \mathrm{~d}$ & & $25 \mathrm{~d}$ & $35 \mathrm{~d}$ \\
\hline AG-06 & $3.60 \mathrm{~ns}$ & $1.5 \mathrm{~ns}$ & & $5.50 \mathrm{c}$ & $10.5 \mathrm{~ns}$ \\
AG-06+GN-2 & 4.55 & 3.0 & & $13.25 \mathrm{~b}$ & 13.0 \\
AG-06+GN-4 & 4.30 & 2.5 & & $5.25 \mathrm{c}$ & 10.5 \\
AG-06+GN-8 & 4.23 & 4.0 & & $15.50 \mathrm{a}$ & 13.5 \\
\hline
\end{tabular}

Different letters in column represent significant differences according to LSD test $(\mathrm{P}<0.05)$. ns: Nonsignificant. 
Table 3. Effect of inoculation of Ensifer meliloti and plant growth promoting rhizobacteria (PGPR) with 1-aminocyclopropane-1-carboxylic acid (ACC) deaminase activity in alfalfa nodule number, nodule dry weight, root length and crown diameter under greenhouse conditions.

\begin{tabular}{lcccc}
\hline Inoculants & Nodule number & Nodule dry weight & Root length & Crown diameter \\
\hline & & $\mathrm{mg}$ & $\mathrm{cm}$ & $\mathrm{mm}$ \\
AG-06 & $11 \mathrm{~b}$ & $0.0033^{\mathrm{ns}}$ & $30.23^{\mathrm{ns}}$ & $1.63^{\mathrm{ns}}$ \\
AG-06+GN8 & $13 \mathrm{~b}$ & 0.005 & 36.83 & 1.96 \\
AG-06+AG-30 & $24 \mathrm{a}$ & 0.0052 & 27.6 & 1.91 \\
CV & 25.55 & 43.85 & 15.14 & 25.65 \\
\hline
\end{tabular}

Different letters represent significant differences according to LSD test $(\mathrm{P}<0.05)$. ns: Nonsignificant; CV: coefficient of variation.

alfalfa. The use of endophytic bacteria with enzymatic activity, in addition to rhizobia with genetic expressions of ACC deaminase, rapidly reduce ethylene levels during the nodulation process (Sarma and Saikia, 2014; Kisiel and Kepczynska, 2016). Ethylene in plants reacts rapidly to environmental and biological stress conditions through transcription of genes encoding a defense response in plants (Glick, 2014). In legume nodulation ethylene blocks the initiation of the infection thread and modulation of the Nod factor, especially under conditions of environmental stress where the concentration of ethylene is induced at levels unfavorable for the development of the plants (Glick, 2014). The dry weight of the nodules and the diameter of the crown obtained for the treatments E. meliloti-PGPR was higher than the treatment inoculated only with E. meliloti (Table 3). There were no differences between treatments in root length and in the crown diameter (Table $3)$. In this experiment, plants were regularly watered and fertilized and were under controlled climatic conditions. Yet, the activity of ACC deaminase strains is known to increase when plants are exposed to stress (Sarma and Saikia, 2014) due to the increase of ethylene, significantly improving growth and symbiotic efficiency during nodulation (Kisiel and Kepczynska, 2016). Therefore, improved plant growth promoting results could be expected from these strains under field or stressful conditions.

\section{CONCLUSIONS}

Plant growth promoting bacterial strains were isolated from the alfalfa rhizosphere in a Chilean dryland soil, showing different growth promoting properties such as indole acetic acid production, phosphate solubilization and 1-aminocyclopropane-1-carboxylic acid (ACC) deaminase activity. The ACC deaminase activity of bacteria associated with the rhizosphere significantly improves early nodulation in alfalfa plants under greenhouse conditions.

\section{ACKNOWLEDGEMENTS}

This study was carried out thanks by the financial support Project FONDECYT N ${ }^{\circ} 11130479$. The authors thank Dr. Bernard Glick, for kindly providing strains with ACC-deaminase activity and mutants.

\section{REFERENCES}

Ali, S., Charles, T., and Glick, B. 2014. Amelioration of high salinity stress damage by plant growth-promoting bacterial endophytes that contain ACC deaminase. Plant Physiology and Biochemistry 80:160-167.

Barnawal, D., Bharti, N., Maji, D., Singh, C., and Kalra, A. 2014. ACC deaminase-containing Arthrobacter protophormiae induces $\mathrm{NaCl}$ stress tolerance through reduced $\mathrm{ACC}$ oxidase activity and ethylene production resulting in improved nodulation and mycorrhization in Pisum sativum. Journal of Plant Physiology 171:884-894.

Barrucha, U., Patel, K., and Trivedi, U. 2013. Optimization of indole acetic acid production by Pseudomonas putida UB1 and its effect as plant growth-promoting rhizobacteria on mustard (Brassica nigra). Agricultural Research 2(3):215-221.

Bouton, J.H. 2012. Breeding lucerne for persistence. Crop and Pasture Science 63:95-106. doi:10.1071/cp12009.

Brader, G., Compant, S., Mitter, B., Trognitz, F., and Sessitscha, A. 2014. Metabolic potential of endophytic bacteria. Current Opinion in Biotechnology 27:30-37.

Chaiharn, M., and Lumyong, S. 2011. Screening and optimization of indole-3-acetic acid production and phosphate solubilization from rhizobacteria aimed at improving plant growth. Current Microbiology 62:173-181. 
del Pozo, A., Ovalle, C., Espinoza, S., Barahona, V., Gerding, M., and Humphries, A. 2017. Water relations and use-efficiency, plant survival and productivity of nine alfalfa (Medicago sativa L.) cultivars in dryland Mediterranean conditions. European Journal of Agronomy 84:16-22.

Duca, D., Lorv, J., Patten, C., Rose, D., and Glick, B. 2014. Indole-3-acetic acid in plant-microbe interactions. Antonie van Leeuwenhoek 106:85-125.

Dworkin, M., and Foster, J. 1958. Experiments with some microorganisms which utilize ethane and hydrogen. Journal of Bacteriology 75(5):592-603.

Egamberdiyeva, D. 2007. The effect of plant growth promoting bacteria on growth and nutrient uptake of maize in two different soils. Applied Soil Ecology 36:184-189.

Ghosh, P., Sen, S., and Maiti, T. 2015. Production and metabolism of IAA by Enterobacter spp. (Gammaproteobacteria) isolated from root nodules of a legume Abrus precatorius L. Biocatalysis and Agricultural Biotechnology 4:296-303.

Glick, B. 2014. Bacteria with ACC deaminase can promote plant growth and help to feed the world. Microbiological Research 169:30-39.

Guiñazú, L., Andrés, J., Rovera, M., Balzarini, M., and Rosas, S. 2013. Evaluation of rhizobacterial isolates from Argentina, Uruguay and Chile for plant growth-promoting characteristics and antagonistic activity towards Rhizoctonia sp. and Macrophomina sp. in vitro. European Journal of Soil Biology 54:69-77.

Hardoim, P., Overbeek, L., and van Elsas, J. 2008. Properties of bacterial endophytes and their proposed role in plant growth. Trends in Microbiology 16(10):463-471.

Ji, Z., Yan, H., Guo, Q., Tao, E., Feng, W., and Xin, W. 2017 Competition between rhizobia under different environmental conditions affects the nodulation of a legume. Systematic and Applied Microbiology 40:114-119.

Kisiel, A., and Kepczynska, E. 2016. Medicago truncatula Gaertn. as a model for understanding the mechanism of growth promotion by bacteria from rhizosphere and nodules of alfalfa. Planta 243:1169-1189.

Ma, W., Charles, T., and Glick, B. 2004. Expression of an exogenous 1-aminocyclopropane-1-carboxylate deaminase gene in Sinorhizobium meliloti increases its ability to nodulate alfalfa. Applied and Environmental 70(10):5891-5897.

Marques, A., Marchaison, A., Gardan, L., and Samson, R. 2008. BOX-PCR-based identification of bacterial species belonging to Pseudomonas syringae-P. viridiflava group. Genetics and Molecular Biology 31(1):106-115.

Masciarelli, O., Llanes, A., and Luna, V. 2014. A new PGPR co-inoculte with Bradyrhyzobium japonicum enhances soybean nodulation. Microbiological Research 169:609-615.

Nascimento, F., Brígido, C., Glick, B., Oliveira, S., and Alho, L. 2012. Mesorhizobium cicero LMS-1 expressing an exogenous 1-aminocyclopropane-1-carboxylate (ACC) deaminase increases its nodulation abilities and chickpea plant resistance to soil constraints. Letters in Applied Microbiology 55:15-21.

Oskouei, D., Bekmen, N., Ellidokuz, H., and Yilmaz, O. 2010. Evaluation of different cryoprotective in maintenance of viability of Helicobacter pylori in Stock culture media. Brazilian Journal of Microbiology 41:1038-1046.

Oufdou, K., Bechtaoui, N., Alaoui, A., Benidire, L., Daoui, K., and Göttferrt, M. 2016. Symbiotic rhizobacteria for improving of the agronomic effectiveness of phosphate fertilizers. Procedia Engineering 138:325-331.

Parsa, S., Ortiz, V., and Vega, F. 2013. Establishing fungal entomopathogens as endophytes: Towards endophytic biological control. Journal of Visualized Experiment 74:e50360. doi:10.3791/50360.

Penrose, D., and Glick, B. 2003. Methods for isolating and characterizing ACC deaminase-containing plant growth-promoting rhizobacteria. Physiologia Plantarum 118:10-15.

Pini, F., Frascella, A., Santopolo, L., Bazzicalupo, M., Biondi, E., Scotti, C., et al. 2012. Exploring the plant-associated bacterial communities in Medicago sativa L. BMC Microbiology 12:78.

Rashid, S., Charles, T., and Glick, B. 2012. Isolation and characterization of new plant growth-promoting bacterial endophytes. Applied Soil Ecology 61:217-224.

Sadzawka, A., Carrasco, M.A., Grez, R., y Mora, M. 2004. Métodos de análisis recomendados para suelos chilenos. 113 p. Comisión de Normalización y Acreditación. Sociedad Chilena de la Ciencia del Suelo, Chillán, Chile.

Sarma, R., and Saikia, R. 2014. Alleviation of drought stress in mung bean by strain Pseudomonas aeruginosa GGRJ21. Plant and Soil 377:111-126.

Sepúlveda-Caamaño, M., Gerding, M., Vargas, M., Moya-Elizondo, E., Oyarzúa, P., and Campos, J. 2018. Lentil (Lens culinaris L.) growth promoting rhizobacteria and their effect on nodulation in coinoculation with rhizobia. Archives of Agronomy and Soil Science 64:2, 244-256.

Shahzad, S., Khalid, A., Arshad, M., Tahir, J., and Mahmood, T. 2010. Improving nodulation, growth and yield of Cicer arietinum L. through bacterial ACC-deaminase induced changes in root architecture. European Journal of Soil Biology 46:342-347.

Sharma, S., Sayyed, R., Trivedi, M., and Gobi, T. 2013. Phosphate solubilizing microbes: sustainable approach for managing phosphorus deficiency in agricultural soils. SpringerPlus 2:587.

Suzaki, T., Ito, M., and Kawaguchi, M. 2013. Genetic basis of cytokinin and auxin functions during root nodule development. Frontiers in Plant Science 4:42.

Tamura, K., Peterson, D., Peterson, N., Stecher, G., Nei, M., and Kumar, S. 2011. MEGA5: Molecular evolutionary genetics analysis using maximum likelihood, evolutionary distance, and maximum parsimony methods. Molecular Biology and Evolution 28(10):2731-2739. 
Truyens, S., Weyens, N., Cuypers, A., and Vangrosveld, J. 2015. Bacterial seed endophytes: genera, vertical transmission and interaction with plants. Environmental Microbiology Reports 7(1):40-50.

Undurraga, P., Hirzel, J., Celis, J., Perez, C., and Sandoval, M.A. 2017. Pelletized paper mill waste promotes nutrient input and N mineralization in a degraded Alfisol. Chilean Journal of Agricultural Research 77:390-399. doi:10.4067/S0718-58392017000400390.

Yadav, J., and Prakash, J. 2014. Effect of seed inoculation with indigenous Rhizobium and plant growth promoting rhizobacteria on nutrients uptake and yields of chickpea (Cicer arietinum L.) European Journal of Soil Biology 63:70-77.

Zafar, M.,Abbasi, M.K., Khan, M.A., Khaliq, A., Sultan, T., and Aslam, M. 2012. Effect of plant growth-promoting rhizobacteria on growth, nodulation and nutrient accumulation of lentil under controlled conditions. Pedosphere 22:848-859. 